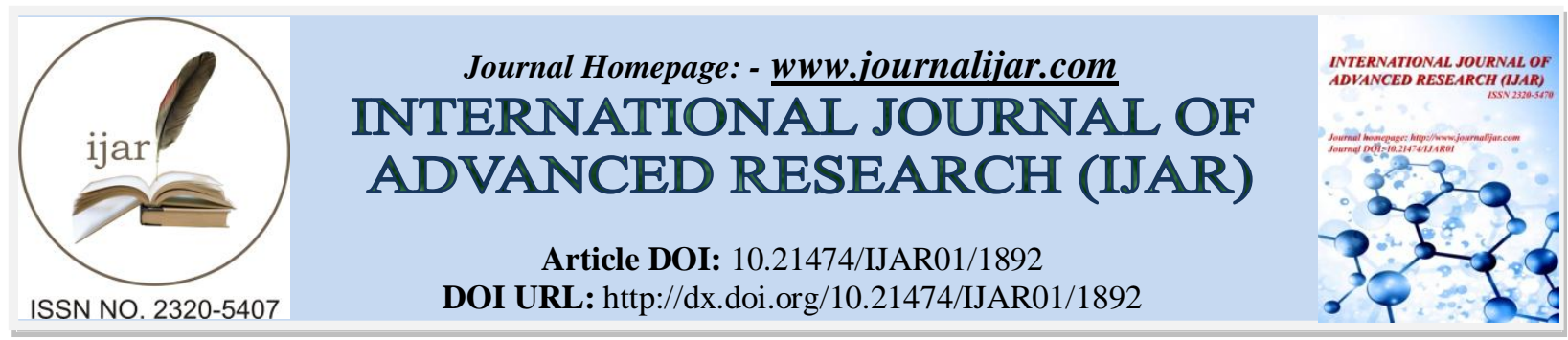

RESEARCH ARTICLE

\title{
STRESS EVALUATION USING DAS SCALE AND SALIVARY CORTISOL IN PATIENTS WITH ORAL LICHEN PLANUS, ORAL SUBMUCOUS FIBROSIS, LEUKOPLAKIA AND SQUAMOUS CELL CARCINOMA.
}

\section{Dr. Sonule Sonal $\mathbf{S}^{1}$, Dr. Chandak Rakhi $\mathbf{M}^{2}$, Dr. Kulkarni Sunita $\mathbf{P}^{3}$, Dr. Gaikwad Ashwini $\mathbf{A}^{4}$, Dr. Akhade} Sonali $\mathbf{N}^{5}$ and Dr. Joshi purushottam $\mathbf{N}^{6}$.

1. $3^{\text {rd }}$ year Post Graduate, Department of Oral Medicine and radiology, Swargiya Dadasaheb Kalmegh Smurti Dental College \& Hospital, Hingna road, Wanadongri, Nagpur, Maharashtra.

2. MDS and Associate Professor, Department of Oral Medicine and radiology, Swargiya Dadasaheb Kalmegh Smurti Dental College \& Hospital, Hingna road, Wanadongri, Nagpur, Maharashtra.

3. MDS, Head and Professor, Department of Oral Medicine and radiology, Swargiya Dadasaheb Kalmegh Smurti Dental College \& Hospital, Hingna road, Wanadongri, Nagpur, Maharashtra.

4. MDS, Professor in conservative dentistry and Endodontia, Bharti Vidyapeeth Deemed university Dental College \& hospital, Pune.

5. MDS, $3^{\text {rd }}$ year Post Graduate, Department of Oral Medicine and radiology, Swargiya Dadasaheb Kalmegh Smurti Dental College \&Hospital, Hingna road, Wanadongri, Nagpur, Maharashtra.

6. MDS, Department of Oral Medicine and radiology, private practitioner, Nagpur, Maharashtra.

\section{Manuscript Info}

Manuscript History

Received: 16 August 2016

Final Accepted: 16 September 2016

Published: October 2016

Key words:-

DAS Scale, leukoplakia ,oral

Submucous fibrosis, Oral lichen planus,

Squamous Cell Carcinoma, Salivary cortisol.

\section{Abstract}

Aim:- the aim of this observational study is to evaluate stress using das scale and salivary cortisol in patients with oral lichen planus(OLP), oral submucous fibrosis(OSMF), leukoplakia and squamous cell carcinoma(SCC).

Method:- A total of 100 patients were included among which 25 subjects were taken into each group. Saliva was collected from all the subjects between 9.00 to 10.00 am to avoid diurnal variation of cortisol levels. The saliva samples were analysed for cortisol levels enzyme linked immunosorbent assay (ELISA) method. Stress, anxiety and depression levels of 100 patients were measured using DASScale. Stress, anxiety and depression among each group was analysed by Chi-square test. Stress, anxiety and depression among each group was compared by salivary cortisol levels in OSMF, Leukoplakia, Lichen planus and Squamous cell carcinoma group by Post-hoc test.

Result:- The mean salivary cortisol level in OLP and SCC group showed highly significant difference when compared to OSMF and leukoplakia. The mean stress, anxiety and depression of OLP and SCC showed highly significant difference when compared to OSMF and leukoplakia. A positive correlation was found between stress, anxiety and depression and salivary cortisol levels in OLP and SCC when compared to OSMF and leukoplakia which showed negative correlation.

Conclusion:- These findings suggest that stress, anxiety and depression plays an important role in pathogenesis of OLP and SCC,

Corresponding Author:- Dr. Sonule Sonal S.

Address:- $3^{\text {rd }}$ year Post Graduate, Department of Oral Medicine and radiology, Swargiya Dadasaheb 
thus early detection of these lesion helps to improve treatment and psychiatric support for these patients.

Copy Right, IJAR, 2016,. All rights reserved.

\section{Introduction:-}

Stress is one of the etiology or predisposing factor in many diseases. In course of time people falls to prey dilitorious habits such as gutkha, tobacco and betel nut chewing, pan chewing, smoking etc which leads to harmful effects on oral mucosa. Some diseases are considered as idiopathic, hence diagnosis and treatment plan of such diseases always becomes controversial. ${ }^{1}$ Oral lichen planus(OLP) $)^{2,3,4}$, oral submucous fibrosis(OSMF) ${ }^{3}$, leukoplakia ${ }^{3}$, squamous cell carcinoma $(\mathrm{SCC})^{2}$ are the most common oral mucosal diseases known to human beings and constitute entities that deserve to be investigated as psychosomatic diseases. Studies have find that $20 \%$ to $40 \%$ of cancer patients have significant levels of distress. ${ }^{2}$ Cortisol "stress hormone" has been used as an indicator in stress evaluation studies. Cortisol is the major glucocorticoid in humans and has a wide range of influences on metabolism, immunoregulation, vascular responsiveness, cognition, and behavior. Salivary cortisol measurement is an indicator of free cortisol or biologically active cortisol in human serum and provides non invasive and easy technique. ${ }^{3}$ In stressful situations, there is an activation of the HPA (hypothalamus-pituitary-adrenal) axis, with release of cortisol, a hormone that shows a complex action on the metabolism of carbohydrates, proteins and lipids, besides acting on inflammatory and immunological responses. ${ }^{5}$

OSMF has become a serious concern to the health care providers as it largely affects the younger age group. During recent years, the important interrelationship between chronic physical illnesses and psychiatric disorders has been studied extensively ${ }^{6 .}$ It is suggested that individuals with chronic somatic diseases like cancers, temporomandibular disorders, burning mouth syndrome, oral lichen planus and recurrent aphthous stomatitis, asthma, arthritis, chronic obstructive pulmonary disease, diabetes mellitus, are at a relatively higher risk of developing psychological distress than physically healthy people. ${ }^{6}$ Psychological distress may manifest itself in many different ways, from having to make an extra effort to cope with illnesses, through emotional symptoms such as grief or anxiety that naturally accompany a fearful situation, to a clear cut psychiatric disorder. ${ }^{6}$

Oral lichen planus is a relatively common chronic disease occurring in 0.2 to $2 \%$ and even $4 \%$ of the population of unknown etiology, which is manifested on the oral mucosa and the skin. The highest incidence of lichen planus is among individuals aged between 30 and 70 years, predominating in women (60\%). Lichen lesions appear bilaterally, most frequently on the distal part of the buccal mucosa. Other sites include lingual, labial, gingival and palatal mucosa. In about $10 \%$ of patients, lesions are detected only on the gums presenting as small, plaques and papule increasing in size, which may imitate keratotic lesions such as leukoplakia. Etiopathogenesis of this disease primarily focuses on immunological disorders, i.e. the presence of cellular reaction with T-lymphocyte activity (mainly CD8 accessory subpopulations) and also genetic (familial) predisposition, as well as psychoneurogenic influences. ${ }^{7,8}$ Patients diagnosed with OLP typically manifest elevated sense of anxiety and depression and higher susceptibility to psychotic disturbances. Such patients are also reported to have high levels of cortisol in their saliva, which confirms the association of this pathology with stress. ${ }^{9}$ Local factors include mechanical, chemical and thermal injuries. New lesions appear on the oral mucosa in response to trauma or irritation (Koebner's response). This observation may explain higher incidence of erosive lesions in areas exposed to persistent irritation (buccal mucosa, lateral borders of the tongue). ${ }^{10}$

Leukoplakia is currently defined as a white lesion of the oral mucosa which cannot be specifically diagnosed as other pathology. It is regarded as a precancerous lesion defined as morphologically altered tissue in which cancer is more likely to occur than its apparently normal counterpart. Leukoplakia may occur anywhere on the oral mucosa and its incidence varies between 1 to $10 \%$ of the population. The factors predisposing to leukoplakia include: tobacco smoking and chewing, Candida albicans infections, HPV (type 16 and 18) infections, atrophic epithelial lesions, persistent trauma, and electrogalvanic current. ${ }^{11}$ Most frequently, leukoplakia manifests itself bilaterally on the buccal mucosa in the vicinity of retromolar areas, less frequently on the lips, the tongue, the gums and the palate. If leukoplakia is located in the floor of the mouth or the ventral or lateral borders of the tongue, the risk of neoplastic transformation is higher. ${ }^{12}$ 
Oral cancer is the 6th most common human cancer in the world, with a high morbidity rate, and a 5-year mortality rate of about $50 \%{ }^{13}$ More than $90 \%$ of oral cancers are squamous cell carcinomas. The Indian subcontinent accounts for one-third of the world burden of this malignancy. Cancer may be defined as an uncontrolled tissue growth in susceptible patient, which result from imbalance between cell division and programmed cell death. It occurs more commonly in males with ratio of $2: 1$, older than 50 years with an average age of 60 years. Most common involved site are the posterior and lateral borders of tongue and lower lip and less frequently the floor of mouth, alveolar mucosa, palate and buccal mucosa. Free radicals, such as reactive oxygen and nitrogen species (ROS and RNS), which induce oxidative and nitrative stress, are principal inducers of OSCC. It has been estimated that as many as $50 \%$ of cancer patients experience symptoms of depression. ${ }^{14}$ The negative impact of depressive symptoms on cancer patients takes many forms, including reduced quality of life, poorer functional status, disruption of social relations, and poorer medical outcomes and possibly reduced survival time. ${ }^{14}$

Our purpose of this study is to assess and confirm stress, anxiety and depression in oral lichen planus, oral submucous fibrosis, leukoplakia and squamous cell carcinoma patients by DAS Scale and estimation of salivary cortisol in patients with increased depression, anxiety and stress level among each subgroup.

\section{Materials and Method:-}

The study was conducted in the department of Oral Medicine and Radiology after approval by institutional ethical committee and Maharashtra University of Health Sciences. This study included total of 100 subjects which were divided into four groups each of 25 subjects. Group A: 25 Oral submucous fibrosis , Group B: 25 leukoplakia, Group C: 25 Oral lichen planus, Group D: 25 squamous cell carcimona Patients with systemic diseases, psychological disorders and undergoing treatment with psychoactive drugs (antidepressants, sedative, narcotics) were excluded from study. Biopsy procedure was performed for histologic confirmation. The study patients age ranging from 15 to 70 were included after their written informed consent. None of the patients had a history of any systemic disease, no history of any prior medications and management. Saliva samples were collected from the subjects between 9.00 to $10.00 \mathrm{am}$, before meal without stimulation by drooling method. The collected samples were stored at $-20^{\circ} \mathrm{C}$ until shortly before assay. Salivary cortisol was measured by Enzyme Linked Inmunosorbent Assay (ELISA) method, by using cortisol ELISA manufactured by Sigma-Aldrich, USA. Normal cortisol values in morning hours normal in range of $3-10 \mathrm{ng} / \mathrm{ml}^{3}$

After saliva collection samples were subjected for psychological evaluation (Depression, anxiety and stress levels) by DAS Scale ${ }^{8}$ questionnaire. This scale consists of 42 questions. The scale consists of 42 questions among which 14 address depression, 14 address anxiety and 14 address stress. The individuals were rated on a four point scale for each of 42 items ranging from $0-3$. The patients with a total score of 9 of depression, 7 of anxiety and 14 of stress comes under normal range and patients having score above $28+$ in depression, 20+ in anxiety and 34+ in stress were included under extremely severe range.

Chi-square test was used to analyse stress, anxiety and depression among each group. Post-hoc test was used to compare stress, anxiety and depression and salivary cortisol levels in Group A,B,C,D.

\section{Results:-}

Data was tabulated, statistical analysis was done and results were obtained. The mean age and SD of 25 SCC patients was 48 yrs \pm 10.45 which was significantly higher as compared to the mean age in 25 leukoplakia patients which was $35 \mathrm{yrs} \pm 8.37,25$ OLP which was $32 \mathrm{yrs} \pm 7.33$ and 25 OSMF patients which was $26 \mathrm{yrs} \pm 6.65$ [Table 1].

Table 1: Comparison of mean age among oral submucous fibrosis, leukoplakia, oral lichen planus, and Squamous cell carcinoma patients.

\begin{tabular}{|c|c|c|c|c|}
\hline Mean & Std. Deviation & $\mathbf{P}^{*}$ Value & & \\
\hline OSMF & 25 & 26.5600 & 6.65257 & \\
\hline Leukoplakia & 25 & 35.2800 & 8.37417 & $<0.001$ \\
\hline Lichen planus & 25 & 32.3600 & 7.33644 & \\
\hline Squamous cell carcinoma & 25 & 48.5600 & 10.45259 & \\
\hline Total & 100 & 35.6900 & 11.53186 & \\
\hline
\end{tabular}

* - One way ANOVA test 
Results from DAS Scale showed that mean stress score in 25 OSMF patients was 9.96\%, 25 leukoplakia patients was $8.80 \%, 25$ patients of OLP $19.56 \%$ and 25 SCC was $20.08 \%$. Mean stress score by DAS Scale in 25 patients of SCC and 25 OLP was higher as compared to 25 OSMF patients and 25 leukoplakia patients. Stress levels were found to be normal in OSMF and leukoplakia group with the post-hoc test. The result was statistically significant with the $\mathrm{p}$ value of $<0.001(\mathrm{p}<0.005)$ [Table 2].

Table 2: Comparision of Mean stress, anxiety and depression among OSMF, leukoplakia, oral lichen planus \& Squamous cell carcinoma patients.

\begin{tabular}{|c|c|c|c|c|c|c|c|}
\hline $\mathbf{N}$ & Iean & $\begin{array}{c}\text { Std. } \\
\text { Deviation }\end{array}$ & $\mathbf{P}^{*}$ Value & $\begin{array}{c}\text { Post-hoc } \\
\text { test }^{\#}\end{array}$ & & & \\
\hline \multirow[t]{5}{*}{ stress } & \multicolumn{2}{|c|}{$\operatorname{OSMF}(\mathrm{A})$} & 25 & 9.9600 & 3.29747 & & \\
\hline & \multicolumn{2}{|c|}{ Leukoplakia(B) } & 25 & 8.8000 & 4.10284 & $<0.001$ & $\begin{array}{c}(\mathrm{A}=\mathrm{B})< \\
(\mathrm{C}=\mathrm{D})\end{array}$ \\
\hline & \multicolumn{2}{|c|}{ Lichen planus(C) } & 25 & 19.5600 & 3.26701 & & \\
\hline & \multicolumn{2}{|c|}{$\begin{array}{l}\text { Squamous cell } \\
\text { carcinoma(D) }\end{array}$} & 25 & 20.0800 & 3.10805 & & \\
\hline & \multicolumn{2}{|c|}{ Total } & 100 & 14.6000 & 6.27485 & & \\
\hline \multirow[t]{5}{*}{ anxiety } & \multicolumn{2}{|c|}{ OSMF } & 25 & 6.4400 & 1.80462 & $<0.001$ & $(\mathrm{~A}=\mathrm{B})<\mathrm{D}<\mathrm{C}$ \\
\hline & \multicolumn{2}{|c|}{ Leukoplakia } & 25 & 5.9600 & 2.03060 & & \\
\hline & \multicolumn{2}{|c|}{ Lichen planus } & 25 & 11.4400 & 2.25610 & & \\
\hline & \multicolumn{2}{|c|}{$\begin{array}{l}\text { Squamous cell } \\
\text { carcinoma }\end{array}$} & 25 & 8.0400 & 1.90351 & & \\
\hline & \multicolumn{2}{|c|}{ Total } & 100 & 7.9700 & 2.92483 & & \\
\hline \multirow[t]{5}{*}{ depression } & \multicolumn{2}{|c|}{ OSMF } & 25 & 9.4000 & 4.60977 & $<0.001$ & $\begin{array}{c}\mathrm{B}<(\mathrm{A}=\mathrm{C})< \\
\mathrm{D}\end{array}$ \\
\hline & \multicolumn{2}{|c|}{ Leukoplakia } & 25 & 6.1600 & 2.59294 & & \\
\hline & \multicolumn{2}{|c|}{ Lichen planus } & 25 & 11.4400 & 3.29242 & & \\
\hline & \multicolumn{2}{|c|}{$\begin{array}{l}\text { Squamous cell } \\
\text { carcinoma }\end{array}$} & 25 & 18.2000 & 4.92443 & & \\
\hline & \multicolumn{2}{|c|}{ Total } & 100 & 11.3000 & 5.90754 & & \\
\hline
\end{tabular}

Mean anxiety score by DAS Scale in 25 OSMF patients was 6.44\%, 25 leukoplakia patiens was 5.96\%, 25 OLP group was $11.44 \%$ and 25 SCC patients was $8.04 \%$. Mean anxiety score in 25 OLP group was significantly higher than 25 OSMF patients, 25 leukoplakia patiens, and 25 SCC patients with the p value of $<0.001$ ( $<<0.005$ ) [Table 2].

Mean depression score by DAS Scale in 25 OSMF patients was 9.40\%, 25 leukoplakia patiens $6.16 \%$, 25 lichen planus patients $11.44 \%$ and in 25 SCC group was $18.20 \%$. Mean depression score by DAS Scale in 25 SCC group was significantly higher than 25 OSMF patients, 25 leukoplakia patiens, and 25 OLP with the $p$ value of $<0.001(\mathrm{p}<0.005)$ [Table 2].

Mean cortisol level in 25 OSMF patients was $5.66 \pm 2.90 \mathrm{ng} / \mathrm{ml}$ and in 25 leukoplakia patients was $6.86 \pm 3.31$ $\mathrm{ng} / \mathrm{ml}$, in 25 OLP was $32.56 \pm 14.52 \mathrm{ng} / \mathrm{ml}$ and in $25 \mathrm{SCC}$ patients was $47 \pm 14.54 \mathrm{ng} / \mathrm{ml}$.Mean cortisol level in 25 OSCC patients and in 25 OLP patients was significantly higher as compared to 25 OSMF and 25 leukoplakia patients by post-hoc test. There was highly significant difference in mean cortisol levels between OSMF, leukoplakia, OLP and SCC patients. The result was statistically significant with the $\mathrm{p}$ value of $<0.001(\mathrm{p}<0.005)$, [graph 3]. 
Graph 1:- Comparision of mean cortisol level in Group A,B,C,D.

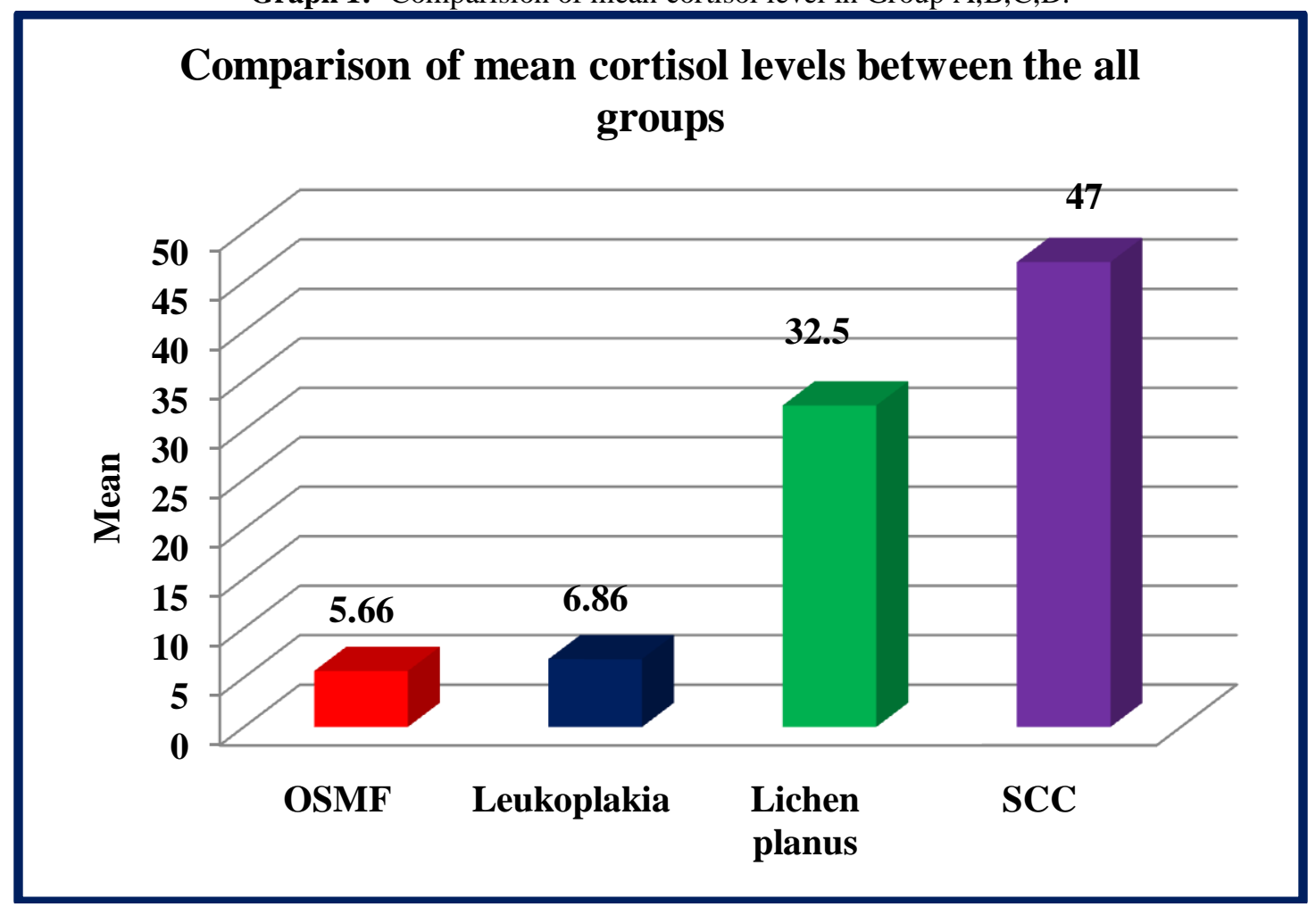

\section{Discussion:-}

It is believed that high anxiety level causes increase in serum and salivary cortisol level and has been used as an indicator in the stress, anxiety and depression evaluation studies. In conditions involving pain and anxiety many metabolic and endocrine changes occur, and among these a rise in the levels of serum as well as salivary cortisol which is one of the most important physiological effects. Cortisol can be measured in urine, plasma and saliva. Collection of serum cortisol is an invasive method as it involves collection of blood, patient may develop anxiety because of fear of withdrawing blood and may give false cortisol values, compared to secretion of cortisol in saliva which is a noninvasive method and a reliable indicator of serum cortisol level. Thus the use of saliva sampling which is a reliable, non-invasive and easy procedure is advocated in the present study. ${ }^{5}$ Several studies have suggested the relationship between salivary cortisol level and stress, anxiety and depression levels. ${ }^{15}$

In oral lichen planus (OLP) patients typically manifest elevated sense of anxiety and depression and higher susceptibility to psychotic disturbances. Such patients are reported to have high levels of cortisol in their saliva, which has confirm the association of this pathology with stress. ${ }^{7}$ Oral submucous fibrosis and leukoplakia are the main premalignant diseases leading to oral carcinoma which is a very important matter of concern in the current scenario.

In carcinoma patients, development of carcinogenesis disturbs the immune system which contributes to stress and also suppress the activity of natural killer cells which may be sufficient enough to cause enhanced tumor development ${ }^{13}$. An important factor of cancer progression is Depression which acts by modifying the modulation of the development and accumulation of genomic instability and somatic mutations. ${ }^{14}$

In present study OSMF group and leukoplakia group had normal levels of stress, anxiety and depression and salivary cortisol level was also within normal range. Up till now there is no such study to compare using DAS scale and salivary cortisol level in OSMF and leukoplakia patients.

Oral lichen planus patients showed higher than normal stress, anxiety and depression levels when evaluated by DASScale which was in accordance with by Shah B et $\mathbf{a l}^{3}$, Kalkur $\mathbf{C}$ et $\mathbf{a l}^{\mathbf{1 6}}$, showed higher stress, anxiety and depression levels than normal evaluated by DASScale. Studies by Pekiner FN et al. ${ }^{17}$, who stated that higher 
anxiety level in OLP compared to healthy individuals and Patil AR et $\mathbf{a l}^{\mathbf{1 8}}$, Bansal et $\mathbf{a l}^{\mathbf{1 9}}$, D Adoma et $\mathbf{a l}^{\mathbf{2 0}}$, Sawant NS et $\mathbf{a l}^{21}$ also found higher anxiety and depression levels in OLP patients but using different psychometric tests which were in accordance with present study which proves strong association of OLP with stress, anxiety and depression levels.

Salivary cortisol values in OLP group was higher than normal range $32.56 \pm 14.52 \mathrm{ng} / \mathrm{ml}$, which was in accordance with Girardi C et al. ${ }^{22}$, Rabiei M et al.2012 ${ }^{23}$, Mohan et $\mathbf{a l}^{24}$ observed higher stress, anxiety and depression levels and higher salivary cortisol values than normal range. Nadendla LK et al. ${ }^{25}$ observed higher salivary cortisol level which was $17.0 \pm 3.82 \mathrm{ng} / \mathrm{ml}$ compared to normal individual. Zenouz AT et al. (2014) ${ }^{26}$ observed higher salivary cortisol level which was $14.5 \mathrm{ng} / \mathrm{ml}$.

Our study results constrated with Hirota SK et al. (2013) ${ }^{27}$ which found that there was no statistically significant difference in the anxiety and depression scores in oral lichen planus patients and control group therefore proves negative correlation of OLP with psychological status and Nosratzehi T et al. ${ }^{28}$ observed higher anxiety scores which was in accordance with our study but lower levels salivary cortisol $3.2 \pm 1.9 \mathrm{ng} / \mathrm{mL}$ within normal range which contrasted with present study.

In SCC group stress and depression level was higher than normal when assessed by DAS Scale, which correlated with Hann D et al. ${ }^{29}$ in (2002) who observed higher depression score in cancer patients of older age group compared to females and younger age patients. Also the salivary cortisol level was higher than normal range which was consistant with Bernabe DG et al. ${ }^{\mathbf{3 0}}$ who observed higher plasma and salivary cortisol level in oral squamous cell carcinoma patients compared to oropharyngeal carcinoma, leukoplakia, smokers and healthy patients.

\section{Conclusion:-}

From the present study it can be concluded that DAS Scale is useful in assessing psychological state of patient which can be correlated with salivary cortisol level.

1. Result from DAS Scale conclude that depression, anxiety and stress level were higher in OLP and SCC groups when compared to OSMF and leukoplakia group which were within normal range.

2. Salivary cortisol level was higher in OLP and SCC groups when compared to OSMF and leukoplakia group which were within normal range.

3. A positive correlation was found between psychological factors (Depression, anxiety and stress) and salivary cortisol levels in oral lichen planus and oral squamous cell carcinoma.

4. A negative correlation was found between psychological factors (Depression, anxiety and stress) and salivary cortisol levels with oral submucous fibrosis and leukoplakia.

\section{References:-}

1. TN Umamaheswari, N Gnanasundaram. Stress related oral diseases. IJPBS 2010;1(3):1-10.

2. Derogatis LR, Marrow GR, Fetting, et al. The prevalence of psychiatric disorders among cancer patients. JAMA $1983 ; 249(6): 751-7$.

3. Shah B, Ashok L, Sujatha GP et al. Evaluation of salivary cortisol and psychological factor in patients with Oral Lichen Planus. Indian J Dent Res 2009;20:288-292.

4. Dagli RJ, Kumar S, Mathur A et al. Prevalence of leukoplakia, oral submucous fibrosis, papilloma and its relation with stress among green marbles mine laborers, India. Med Oral Patol Oral Cir Bucal 2008;13(11):68792.

5. Arlt W, Stewart PM. Adrenal corticosteroid biosynthesis, metabolism, and action. Endocrionol Metab Clin North Am 2005;34(2):293-313.

6. Verhaak PF, Heijmans MJ, Peters L, et al. Chronic disease and mental disorder. Soc Sci Med 2005;60:789-97.

7. Macleod RI. Psychological factors in oral lichen planus. Br Dent J 1992;173(3):88.

8. McCartan BE. Psychological factors associated with oral lichen planus. J Oral Pathol Med 1995;24(6):273-5.

9. Ismail SB, Kumar SK, Zain RB. Oral lichen planus and lichenoid reactions: etiopathogenesis, diagnosis, management and malignant transformation. J Oral Sci 2007;49:89-106.

10. Buajeeb W, Petcharat Kraivaphan P, Amornchat C, Triratana T. Frequency of micronucleated exfoliated cells in oral lichen planus. Mutat Res 2007;627:191-6.

11. Auluck A, Pai KM. Interpretations of leukoplakia. J Can Dent Assoc 2005;71:237-8. 
12. Axell T, Pindborg JJ, Smith CJ, van der Waal I. International Collaborative Group on Oral White Lesions: Oral white lesions with special reference to precancerous and tobacco-related lesions: conclusions of an international symposium held in Uppsala, Sweden, May 18-21 1994. J Oral Pathol Med 1996;25:49-4.

13. Chi AC, Lampert III PR, Pan Yi, Li R, Vo DT, Edwards E, Gangarosa P, Neville BW. Is alveolar ridge keratosis a true leukoplakia. A clinicopathologic comparison of 2,153 lesions. JADA 2007;138:641-65.

14. Małgorzata RO, Magdalena M. Differential diagnosis of oral leukoplakia and lichen planus - on the basis of literature and own observations. J Stoma 2011;64:355-370.

15. McCartan BE, Lamey PJ, Wallace AM. Salivary cortisol and anxiety in recurrent aphthous stomatitis. J Oral Pathol Med 1996;25(7):357-9.

16. Kalkur C, Sattur AP, Guttal KS. Role of depression, anxiety and stress in patients with oral lichen planus: a pilot study. Indian J Dermatol 2015;60(5):445-9.

17. Pekiner FN, Borahan MO, Ozbayrak S et al. Evaluation of levels of cortizol, anxiety and depression in patients with oral lichen planus (Olp). Musbed 2014; 4(1):24-8.

18. Pati AR, Khan M, Ramachandra VK, Panigrahi R, Kabasi S, Acharya SS et al. Psychiatric morbidity in oral lichen planus: a preliminary study. J Indian Acad Oral Med Radiol 2014;26:19-23.

19. Bansal H, Dua V, Sandhu SV, Sandhu JS. Oral Lichen Planus And Stress: An Appraisal. Contemporary Clinical Dentistry 2014;5(3):352-6.

20. D Adamo, E Ruoppo, S Leuci, M Aria, M Amato, MD Mignogna. Sleep disturbances, anxiety and depression in patients with oral lichen planus: a case-control study. JEADV 2015;29(2):291-7.

21. Sawant N, Vanjari NA, Khopkar U, Adulkar S. A study of depression and quality of life in patients of lichen planus. Scientific World J 2015;817481:1-6

22. Girardi C, Luz C, Cherubini K. Salivary cortisol and dehydroepiandrosterone (DHEA) levels, psychological factors in patients with oral lichen planus. Arch Oral Biol 2011;56:864-8.

23. Rabiei M, Sadegh-Kanjani M, Kazemnezhad-Leili E, Kohanghadam S. The comparison between anxiety, level of salivary cortisol \& SIgA in oral lichen planus. J Res Dent Sci 2011;3(33):125-31.

24. Nadendla LK, Meduri V, Paramkusam G, Pachava KR. Association of salivary cortisol and anxiety levels in lichen planus patients. JCDR 2014;8(12):ZC01-03.

25. Zenouz AT, Mehdipour M, Dadashzadeh H, Rafieyan S. Evaluation of relationship between salivary cortisol levels and stress intensity in oral lichen planus patients. Der Pharmacia Lettre 2014;6(6):459-61.

26. Hirota SK, Morena RA, Dos Santos Ch, Seo J, Migliari Da. Psychological profile (anxiety and depression) in patients with oral lichen planus: a controlled study. Minerva Stomatol 2013;62(3):51-6.

27. Nosratzehi T, Arabai-Kalati F, Salimi S, Honarmand E et al. The evaluate of psychological factor and salivary cortisol and Iga levels in patients with oral lichen planus. ZJRMS 2014;16(7):31-4.

28. Hann D, Baker F, Denniston M, Gesme D, Reding D, Flynn T et al. The influence of social support on depressive symptoms in cancer patients age and gender differences. J Psychosom Res 2002;52: 279-83.

29. Bernabe DG, Tamae AC, Miyahara GI, Sundefeld Ml, Oliveria SP, Biasoli ER. Increased plasma and salivary cortisol levels in patients with oral cancer and their association with clinical stage. J Clin Pathol 2012;65(10):934-9. 